\title{
Smart Fast Motion Estimation Processors
}

\author{
M.Ramamoorthy, N.Ayyanathan, M.Padma Usha, S.Franklin
}

\begin{abstract}
This Paper displays an adaptable and versatile movement estimation processor fit for supporting the handling prerequisites for top notch (HD) video utilizing the H.264 Advanced Video Codec, which is appropriate for FPGA execution. This paper dependent on General Purpose processor plan for movement estimation process. Quick movement estimation calculation with full pursuit calculation and precious stone hunt calculation. Where the two calculations have been executed in a solitary processor. So client can powerfully pick as per best execution. A client can choose the alternative of video quality at run time. In contrast to most past work, our center is enhanced to execute all current quick square coordinating calculations, to coordinate or surpass the between casing expectation execution of full-seek approaches at the HD goals generally being used today. Different tale movement estimation designs have been proposed all through the writing for dealing with the high data transfer capacity imperative nature of Video Broadcasting. A High precision full pursuit fixed square inquiry calculation is used to lessen the general transmission capacity and power prerequisite for transmitting live video arrangements. Despite the fact that full hunt guarantees high exactness, it tradeoffs its calculation time for precision. So the precision advantage is emphatically obscured by working velocity. To supplant the Full inquiry calculation another Modified Diamond seek calculation has been proposed with best precision and streamlined movement estimation length. Execution assessment of FBS Full hunt and Diamond look will be thought about for future investigation.
\end{abstract}

Index-FPGA, Motion Estimation, Full Search, Diamond Search,Fixed block Search, variable block search, video codec.

\section{INTRODUCTION}

Movement estimation (ME), Motion estimation (ME), which is the most essential piece of any methodology for video altering, experiences and endeavors to confine the common surplus between dynamic corners. ME, which is computationally serious, contains roughly $80 \%$ of the encoder's complete registering quality.

\section{A .Motion estimation}

The encoder utilizes an item movement model between corners to gage the movement that happened between the reference case and the present outskirt. This is viewed as

Revised Manuscript Received on July 22, 2019.

M. Ramamoorthy, Department of CSE, Bharath Institute of Higher Education and Research, Chennai, Tamilnadu, India.

N.Ayyanathan, Department of CSE, B.S. Abdur Rahman Crescent. Institute of Science \& Technology, Chennai, India

M.Padma Usha, Department of CSE, B.S. Abdur Rahman Crescent. Institute of Science \& Technology. Chennai, India

S.Franklin, , Student,Department of CSE, Bharath Institute of Higher Education and Research, Chennai, Tamilnadu, India evaluating movement.

To generate calculation of motion assessment, there are three items to be chosen. They are calculation of block coordination, calculation of search for measurement of motion and calculation of type of measurement of motion.

There is therefore a need for square coordination. There are two conventional motion assessment techniques: pixel (pel)-recursive calculation (PRA) and calculation of circle coordination (BMA). PRAs are iterative refining of movement estimation for individual pels by angle strategies. BMAs expect that every one of the pels inside a square has a similar movement action.

BMAs gage rectangular square-based motion and generate one vector of motion for each square. PRAs include increasingly multifaceted computing nature and less normality, so in hardware they are difficult to recognize. When all is said in done, BMAs are progressively appropriate for a basic equipment acknowledgment in light of their consistency and effortlessness.

Estimation of the square coordinating motion (BMME) is one of the most efficient and common methods for evacuating the fleeting repeat between progressive corners. Video description is divided into 1616 pixel maps recognized as large-scale squares (MBs) in this approach. For every MB in the ebb and flow outline, one scans for the best coordinated square (inside a hunt run).

The movement vector (MV) is characterized as the dislodging in the reference picture between the present segment place and the best coordinated one. This activity will be repeated until MV is found in the present case for every one of the tiles. To improve the coding capacity, variable squares measure (VBS) ME has been gotten in present day coding norms like H.264. The BMME method's arranging model quickly impacts the gainfulness of coding and computational unpredictability. Many sorting out criteria have been proposed recorded as a printed version, for example, mean square bungle, whole of most noteworthy differentiations (SAD), depiction of pel refinements, and so forth.

Like the MSE measure, the complete ultimate contrast (SAD) also allows the blunder appreciations as beneficial, but instead of summing up the square images, the results are summed up. The SAD measure at removal (I, j) is characterized as,

$$
S A D(i, j)=\frac{1}{N^{2}} \sum_{n_{1}=0}^{N-1} \sum_{n_{2}=0}^{N-1}\left[s\left(n_{1}, n_{2}, k\right)-s\left(n_{1}+i, n_{2}+j, k-l\right)\right]
$$

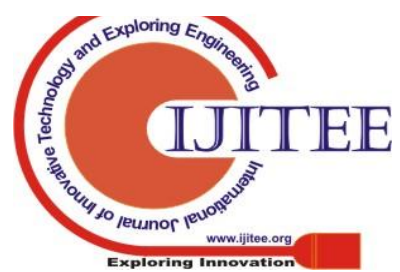


The motion vector is determined in a manner similar to that for MSE as

$$
\left[d_{1}, d_{2}\right]=\arg \underbrace{\min }_{i, j}[S A D(i, j)]
$$

The SAD rule appeared in condition requires N2 calculations of subtractions with outright qualities and increases $\mathrm{N} 2$ for every hopeful square at each pursuit position. The nonattendance of augmentations makes this basis computationally progressively appealing and encourages simpler equipment execution.

Video Enhancement for Medical and Surveillance Applications by Ramamoorthy et al. [21]. Proposed the figuring of establishment subtraction using dynamic edge and a mix of Gaussian three captivating procedures were used reasonably for article affirmation and broke down their reason of execution on the precise region and zone. In laparoscope remedial philosophy, a camera and light offer examination to the master, who sees the extensive and video upgraded wary bits on a TV screen. The video insight system traces contrasts, after the thing front line reaction, and advancement were settled.

\section{BLOCK MATCHING MOTION ESTIMATION ALGORITHM}

Via cautiously concentrating all the applicant deters inside the pursuit window, complete examination (FS) computation gives the ideal worldwide option (for example the base adjusting bungle point over the pursuit window) to evaluate the movement, while a noteworthy gauge of the computational strain is required. To conquer this constraint, many quick square planning estimations (BMAs) have been grown, for example, 2-D logarithmic journey (LOGS), 3-advance inquiry (TSS), conjugate bearing sweep (CDS), cross chase (CS), new 3-advance pursuit (NTSS), 4-advance hunt (4SS), square-based point drop search (BBGDS) and so forth. These quick BMA experience special output models and search for procedures to locate the ideal vector of movement with unquestionably diminished measure of centered interests as thought about and the count of FS.

\section{A. Full Search Algorithm}

It is basic to think about the present square and all the contending maps of the reference diagrams so as to get the most elevated match prevention in the reference segment. The appraisal of full examination movement decides the total incomparable complexity (SAD) gratefulness in each possible area in the inquiry window.

All candidate squares focused for the significant chase window were represented by full hunting.
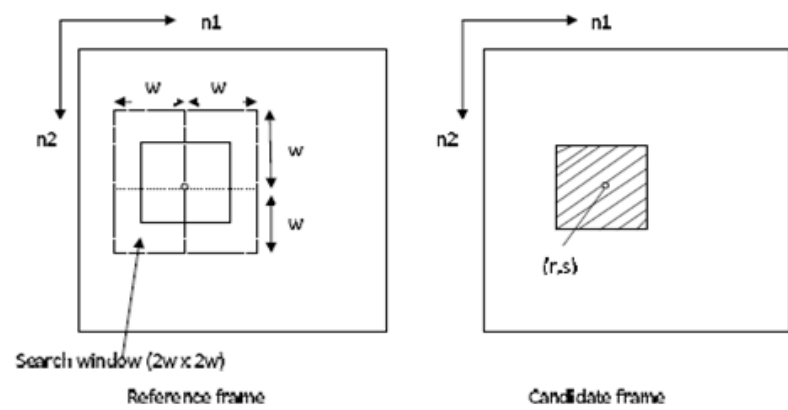

Fig.1: Full Search Motion Estimation

Consider a grid of $\mathrm{N}$-molded $\mathrm{N}$-pixels plot by the competitors at the game plan place (r, s) as appeared, at that point envision an examination board with an extent of $\pm \mathrm{w}$ in both and headings in the reference segment as appeared. For each of the $(2 w+1) 2$ spot of examination (tallying the push force and the reference sketch stream part), the contender square is differentiated and a square of size $\mathrm{N} \times \mathrm{N}$ pixels, as shown by one of the organizing criteria and the best planning square, close by the development vector is settled just after all the $(2 \mathrm{w}+1) 2$ search position are altogether researched.

The FSBM is optimal as it is guaranteed that the best coordinating location is decided if the search extension is efficiently defined. Whatever it may be, it is extremely severe in terms of computation. For each coordinating position, we require $\mathrm{O}(\mathrm{N} 2)$ calculations (options, Method Computations, Add/sub Multiplication, Comparison, subtractions, duplications and so forth.) and since there are seek positions, the quantity of calculations for each coordinating basis is given by Table 1 FSBM requires vast number of calculations

\begin{tabular}{|c|c|c|c|}
\hline Method & \multicolumn{3}{|c|}{ Computations } \\
\hline & Add/sub & Multiplication & Comparison \\
\hline MSE & $\left(2 N^{2}-1\right)(2 w+1)^{2}$ & $N^{2}(2 w+1)^{2}$ & $(2 w+1)^{2}$ \\
\hline SAD & $\left(2 N^{2}-1\right)(2 w+1)^{2}$ & - & $(2 w+1)^{2}$ \\
\hline MPC & $\left(2 N^{2}-1\right)(2 w+1)^{2}$ & - & $N^{2}(2 w+1)^{2}$ \\
\hline
\end{tabular}

\section{B. Computational Complexity of FSBM}

Full-examine scans widely for the vector of movement that restricts a standard, for example, the Sum of Absolute Differences (SAD), inside a predefined search run. The SAD is the most mainstream execution metric utilized between fringe desires as it is easy to discover and is effective in equipment refreshing. On account of its ordinary information stream, this strategy has been usually favored for equipment usage, making it reasonable for structures utilizing 1-D or 2-D systolic presentation standards that just include major control and can accomplish overwhelming equipment use.

Furthermore, full-look structures have the additional advantage of being set up to perform SAD reuse forms that make them especially appropriate for helping the variable square measurements utilized in H.264. By joining the SAD for littler square sizes in bigger sizes, just little augmentations are required in the entryway examine over their conventional fixed-square bands together 
with little course at their throughput, essential way, and memory information transmission.

Then again, the equipment necessities expected to get enough parallelism to check all the conceivable inquiry focuses' continuously are huge. Sequential designs can be utilized to decrease these prerequisites to the detriment of throughput. This turns out to be significantly additionally testing if expansive inquiry ranges, rate-bending streamlining (RDO), and fragmentary pel look are considered.

\section{Diamond Search Algorithm}

In spite of the way that the standard figuring of FS plays out the best quality among various counts of Motion Estimation (ME) and is immediate and has been viably performed on VLSI chips, its computational complexity is incredibly high. Interestingly, continuous and reduced review and sound devices include ultra-computationally effective video codec plans to consider a solid and trustworthy video quality.

The suggested DS calculation basically uses two search models for a scan design for the easy anticipation of the current motion vector that is originally digressed from the casings. The main instance, called significant precious stone hunting layout (LDSP) presented in Figure 3 (an), includes nine inspection points from which eight include the inside one to form a jewel shape. The second instance of five checking revolves a little jewel shape frames, called little valuable rock investigation layout (SDSP), emerged in Figure 3(b). In the DS calculation's looking methodology, LDSP is used over and over until the inside point of the base circle contortion (MBD) occurs. The hunting layout is then altered from LDSP to SDSP when the last organic chase is achieved.

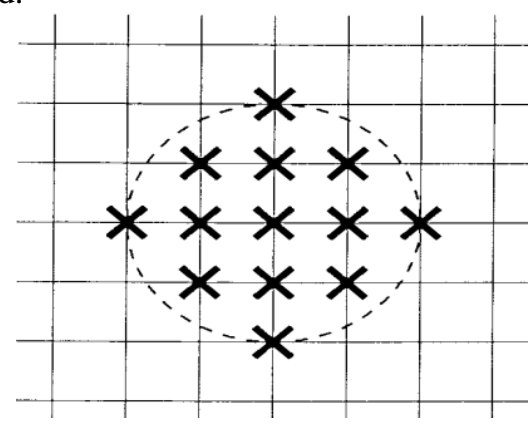

Figure2.An appropriate search pattern support circular area with a radium of 2 pels.

The 13 crosses show all possible checking points within the circle.

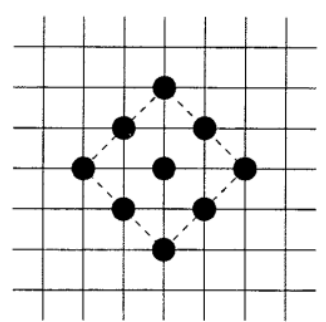

(a) Large diamond yearch pattern (LDSP)

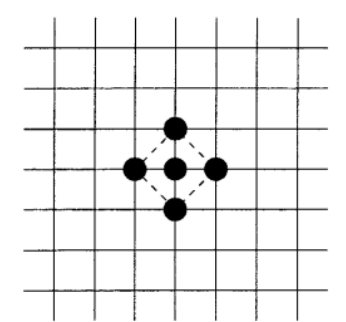

(b) Small diamond search pattern (SDSP) [
Fig 3. (a) Large Diamond Search Pattern (b) Small Diamond Search Pattern
1. Toward the start of the request window, the basic LDSP is engaged and the LDSP's 9 checking designs are attempted. In the event that the decided MBD point is in within spot, go to Step 3 ; go to Step 2 as a rule.

2. As within stage to picture another LDSP, the MBD point found in the past pursue stage is re-orchestrated. If the fresh MBD point is in the center spot, go to Step 3 ; generally, go over this improvement recursively.

3. Change the LDSP to SDSP pursue format. The MBD point found in this advancement is the movement vector's keep going plan that depends on the best adjusting circle.

The preservationist condition of the pursuit models utilized in the DS estimation makes the likelihood of finding minimal point in the pursuit format all around. In contrast to TSS, NTSS and 4SS, the estimation of the inquiry range isn't confined by the DS count search system.

DS calculations can not just gives comparative or as a rule preferable outcome over TSS, but decreases $75 \%$ complexity.but it give the idea that DS has noteworthy quality debasement with grouping containing worldwide estimation or when coding higher goals arrangement.

OVERALL BLOCK DIAGRAM

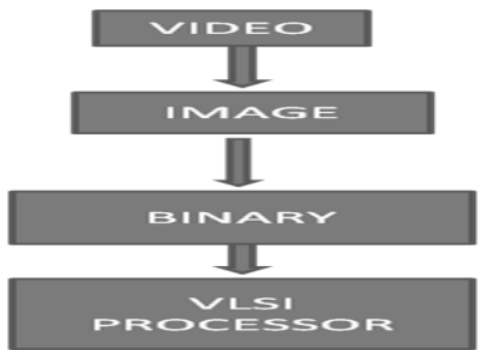

\section{Image to Binary Conversion}

Design of motion estimation processor requires a image to binary conversion module. A chip is capable of handling binary patterns.

Thresholding method is used to covert the integer image pixels into corresponding binary values.

\section{E. Thresholding}

By analyzing the histogram of the image, the maximum occurrences of a particular pixel can be assumed as Background value (threshold).

If the image pixel img $(\mathrm{i}, \mathrm{j})$ is greater than Threshold, then resultant bit is 1 .Else resultant bit is 0 .

\section{F. BinaryToVlsi Processor}

Using file handling the image frames which has been converted into binary numbers can be loaded into register array

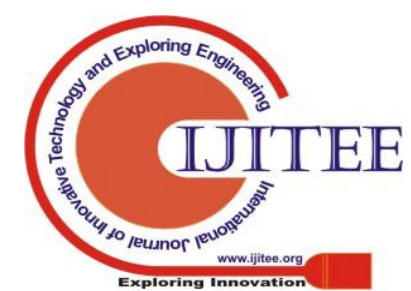




\section{HARDWARE ARCHITECTURE}

\section{A. Top Level Architecture}

The figure indicates H.264/AVC top measurement format for a coprocessor movement appraisal. In the advancement estimation processor, there are four essential units, to be express the pixel memory, managing appear, address age unit and improvement vector memory. Reliably, there are two recollections verifying pursue region and current square pixels. The feature of dealing with is expected to exhibit the essential SAD. The age unit of the spot chooses the addresses in memory for the related data. The moderate condition of the pursuit models utilized in the DS figuring makes the likelihood of finding minimal point in the pursuit design all around. In contrast to TSS, NTSS and 4SS, the estimation of the pursuit range isn't limited by the DS figuring search procedure. Particular spot age calendars are utilized for various chase counts. The ensuing SADs and movement vectors are put away in a limited quantity of memory available by methods for an outer vehicle that functions as an association between the development estimation processor and an extensively valuable processor. [12]

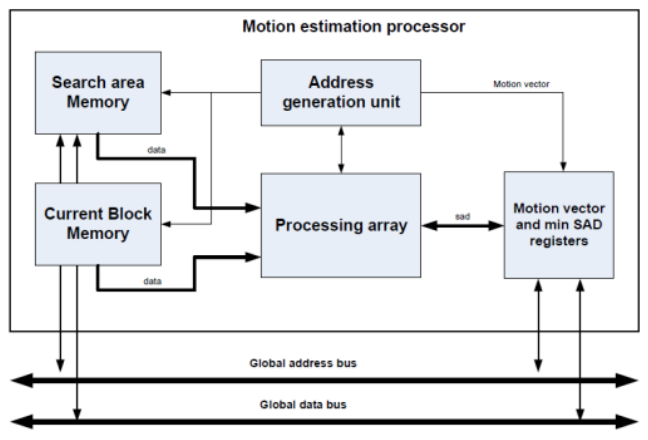

Fig 4. Top level architecture

\section{B. Detailed Architecture}

The square chart of the suggested designing for the usage of DS to perform FBS ME on twofold screens was showed up in Fig. 4. The structure incorporates 8 RAMs to store all the chase screen images (SW), a vault board to store the present pixels, a library board to store the test pixels called the' test vault board,' an information selector set, nine PEs, a comparator and a method control unit.

The examinations of the contrasting model for every one of the 9 spots are coordinated related in the proposed system. Since there are 9 DS figuring search puts, a total of 9 PEs are used. Before the start of ME process for each MB, the interest pixels from the entire SW are stacked into within memory of the ME gear which includes 8 RAMs.

The rectangular sketch of the proposed model by actualizing DS to perform FBS ME on parallel housings has been appeared in Fig. 4. The building comprises of 8 RAMs to expel every one of the pixels from the examination board (SW), a register bunch to evacuate the recurring pattern pixels, a register show to evacuate the pursuit pixels called the' look register group,' a data selector display, nine PEs, a comparator and a strategy control unit.

The evaluations of the coordination rule for all 9 fields are carried out in conjunction in the suggested scheme. Since there are 9 DS calculation search regions, an aggregate of 9 PEs is used. The interest pixels of the whole SW are stacked in within memory of the ME gear, which comprises of 8 RAMs, before the beginning of the ME procedure for every MB. Furthermore, the $\mathrm{CB}$ pixels are set in the register cluster to evacuate the present pixels.

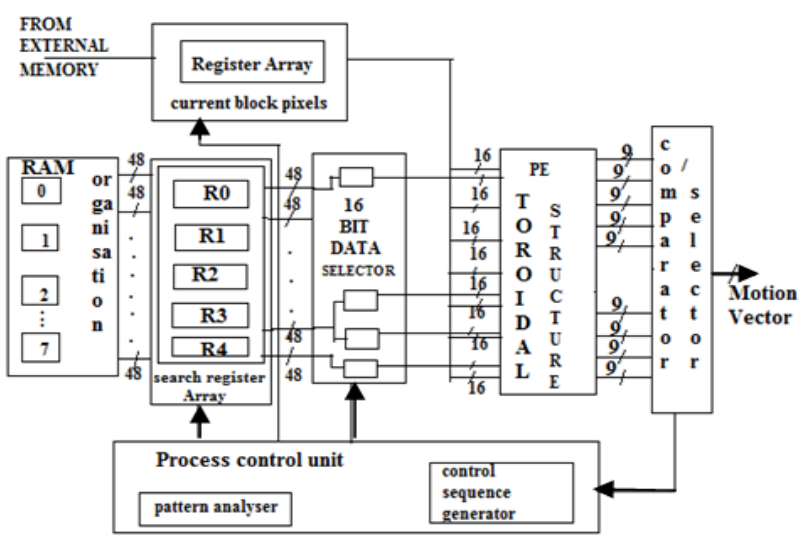

Fig 5.Detailed Architecture

The focus of inquiry is selected as the starting point in the initial step of ME and the look pixels required to figure the coordinating criteria in the middle are stacked in the 8 RAMs hunt register display. At that stage, the search register cluster provides each of the PEs valid investigation pixels. Each of the PEs starts the coordination paradigm (NNMP) evaluation for all the 9 seek areas at the same time. The NNMPs ' plotted evaluations are sent to the comparator. The comparator will discover the NNMP base worth simply like the related area and send it to the control unit of the strategy. The methodology control unit controls the entire system of ME by sending fitting control signs to all the gear modules.

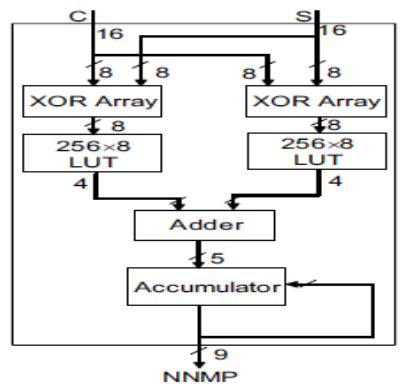

Fig6. PE Architecture for FBS ME

PE's designing is appeared in Fig. 6. In particular, the PE has two information channels, $\mathrm{C}$ and $\mathrm{S}$ to examine two 16-bit streams freely from the $\mathrm{CB}$ and the SW. There are two showcases of 8-bit XOR in the PE. One of the XOR showcases works on the eight most basic bits of the 16-bit $\mathrm{C}$ and $\mathrm{S}$ vectors, and the different works on the eight least gigantic pieces remaining. Two investigate records (LUTs) with 28 sections are utilized to gain the measure of those because of the XOR task. The LUT results are then 
connected to a 4-bit wind. The yield of the snake is then associated at the commitment of the aggregator. The yield of the gatherer gives the estimation of the NNMP for a particular region after 16 clock cycles for a $\mathrm{MB}$ of size $16 \times 16$.

The variable square size (VBS) movement estimation has been broadly utilized to improve the execution of the square coordinating calculation. In respect to fixed square size movement estimation algorithms, VBSME give a lot higher pressure proportions and picture quality. In the past algorithms, many quick BMAs were proposed for diminishing the computational multifaceted nature for full Search algorithm. The jewel look calculation on FBS and VBS is connected so as to lessen computational unpredictability, utilization of intensity and PSNR esteem.

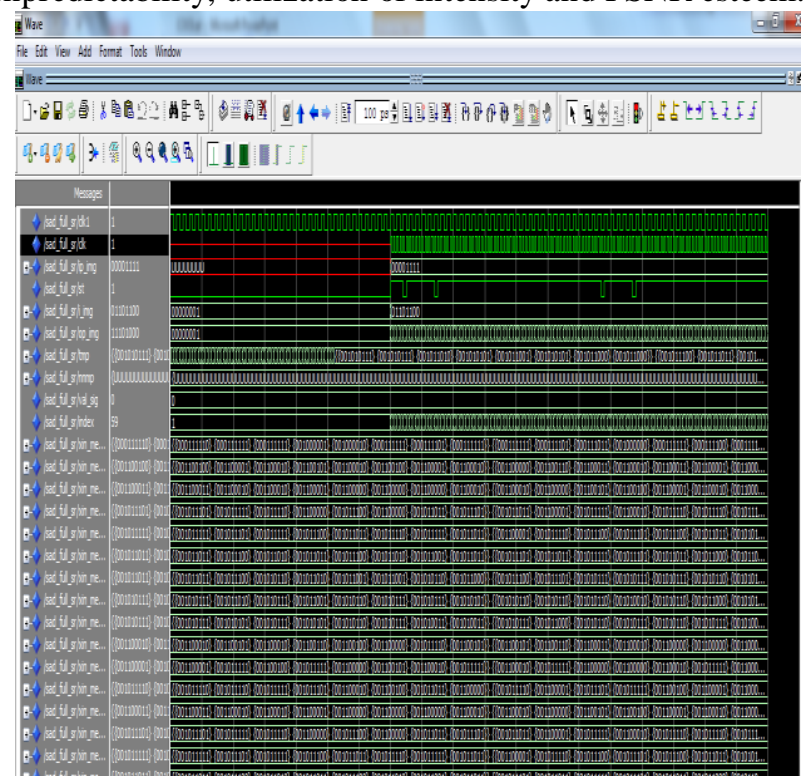

Fig 8.Simulation result of FullSearchFBS

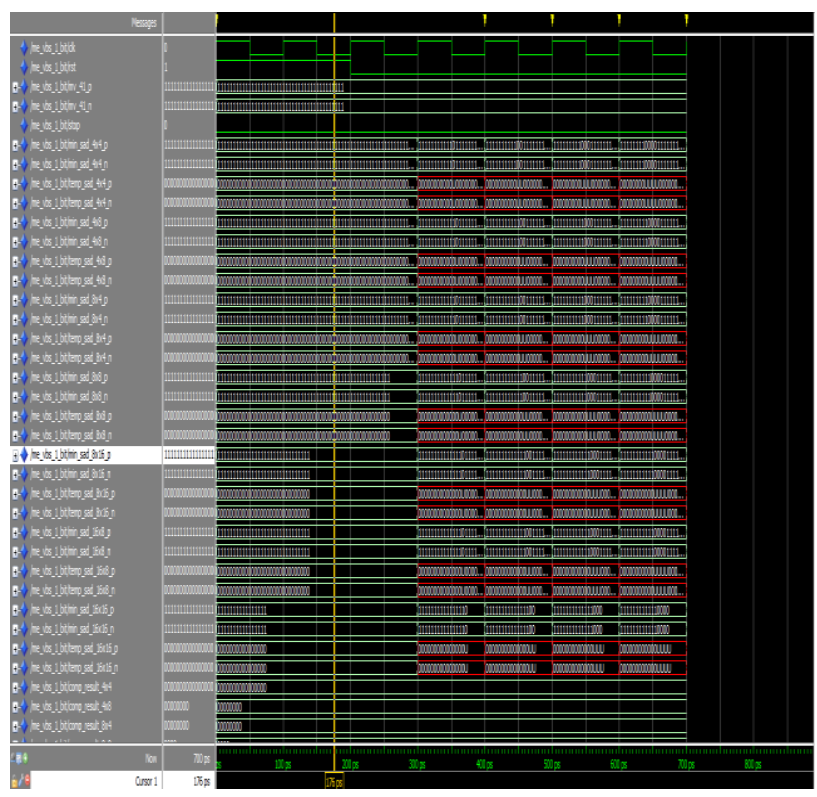

Fig 9.Simulation result of FullSearch VBS

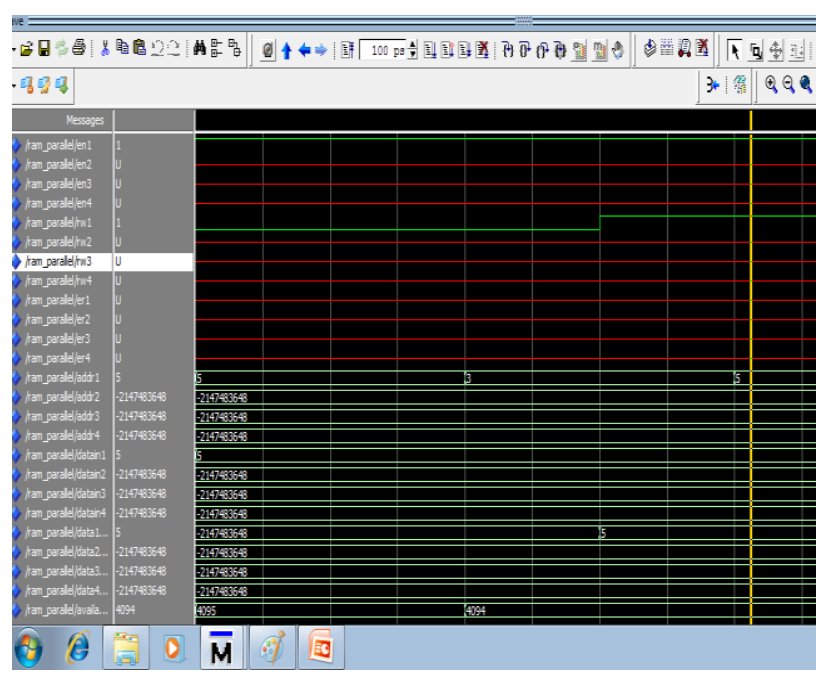

Fig 10.simulation result of diamond search

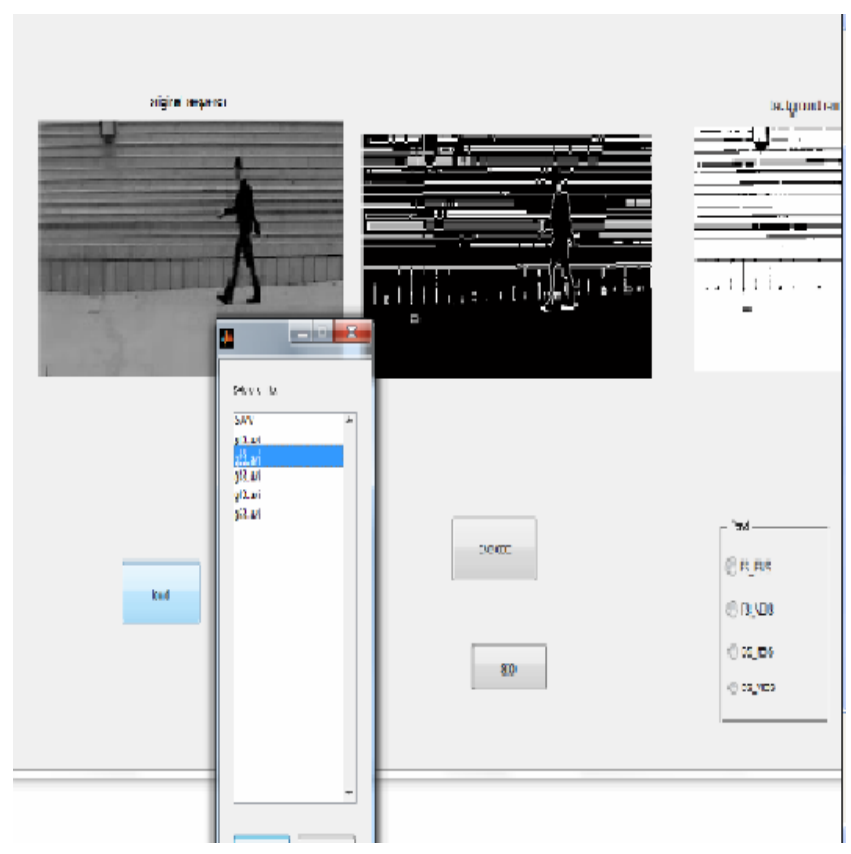

Fig 11.kit implementation result

In this Section,We Presented the Simulation Result of FBS and VBS PE array Structure for full search algorithm and FBS PE array for diamond search algorithm is implemented using VHDL Language in ModelSim.the Full Search Algorithm is evaluated based on performance of SAD Calculation.Full Search Algorithm is the effective method to perform well in term of "Speed-Quality-Bit rate" trade off.

\section{CONCLUSION}

A We our calculations and designs for movement estimation speedup. Results demonstrated that calculations by and large, had higher accelerate and rate-twisting execution at low piece rates, than some past calculations. The proposed designing joins insignificant number of clock cycles required to process a lone MB. The clock repeat required to process a video course of action with a given body size is essentially decreased appeared differently in relation

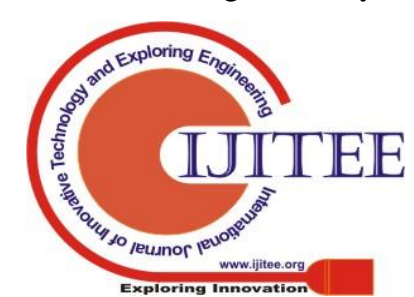




\section{Smart Fast Motion Estimation Processors}

to different architectureEstimation Hardware. Our calculation recommendations are suitable for low-obstruction frameworks, low-bitrate applications and the structure of customer gadgets items requiring continuous handling or pressure at a cheap expense.

\section{REFERENCES}

[1] Kumaravel A., Rangarajan K.,Algorithm for automaton specification for exploring dynamic labyrinths,Indian Journal of Science and Technology,V-6,I-SUPPL5,PP-4554-4559,Y-2013

[2] P. Kavitha, S. Prabakaran "A Novel Hybrid Segmentation Method with Particle Swarm Optimization and Fuzzy C-Mean Based On Partitioning the Image for Detecting Lung Cancer" International Journal of Engineering and Advanced Technology (IJEAT) ISSN : 2249-8958, Volume-8 Issue-5, June 2019

[3] Kumaravel A., Meetei O.N.,An application of non-uniform cellular automata for efficient cryptography,2013 IEEE Conference on Information and Communication Technologies, ICT 2013,V-,I-,PP-1200-1205,Y-2013

[4] Kumarave A., Rangarajan K.,Routing alogrithm over semi-regular tessellations,2013 IEEE Conference on Information and Communication Technologies, $\quad$ ICT 2013,V-,I-,PP-1180-1184,Y-2013

[5] P. Kavitha, S. Prabakaran "Designing a Feature Vector for Statistical Texture Analysis of Brain Tumor" International Journal of Engineering and Advanced Technology (IJEAT) ISSN: 2249-8958, Volume-8 Issue-5, June 2019

[6] Dutta P., Kumaravel A.,A novel approach to trust based identification of leaders in social networks,Indian Journal of Science and Technology,V-9,I-10,PP--,Y-2016

[7] Kumaravel A., Dutta P.,Application of Pca for context selection for collaborative filtering,Middle - East Journal of Scientific Research,V-20,I-1,PP-88-93,Y-2014

[8] Kumaravel A., Rangarajan K.,Constructing an automaton for exploring dynamic labyrinths,2012 International Conference on Radar, Communication and Computing, ICRCC 2012,V-,I-,PP-161-165,Y-2012

[9] P. Kavitha, S. Prabakaran "Adaptive Bilateral Filter for Multi-Resolution in Brain Tumor Recognition" International Journal of Innovative Technology and Exploring Engineering (IJTEE) ISSN 2278-3075, Volume-8 Issue-8 June, 2019

[10] Kumaravel A.,Comparison of two multi-classification approaches for detecting network attacks, World Applied Sciences Journal,V-27,I-11,PP-1461-1465,Y-2013

[11] Tariq J., Kumaravel A.,Construction of cellular automata over hexagonal and triangular tessellations for path planning of multi-robots,2016 IEEE International Conference on Computational Intelligence and Computing Research, ICCIC 2016,V-,I-,PP--,Y-2017

[12] Sudha M., Kumaravel A.,Analysis and measurement of wave guides using poisson method,Indonesian Journal of Electrical Engineering and Computer Science, V-8,I-2,PP-546-548,Y-2017

[13] Ayyappan G., Nalini C., Kumaravel A.,Various approaches of knowledge transfer in academic social network,International Journal of Engineering and Technology,V-,I-,PP-2791-2794,Y-2017

[14] Kaliyamurthie, K.P., Sivaraman, K., Ramesh, S. Imposing patient data privacy in wireless medical sensor networks through homomorphic cryptosystems 2016, Journal of Chemical and Pharmaceutical Sciences 92 .

[15] Kaliyamurthie, K.P., Balasubramanian, P.C. An approach to multi secure to historical malformed documents using integer ripple transfiguration 2016 Journal of Chemical and Pharmaceutical Sciences 9

[16] A.Sangeetha,C.Nalini,"Semantic Ranking based on keywords extractions in the web", International Journal of Engineering \& Technology, 7 (2.6) (2018) 290-292

[17] S.V.GayathiriDevi,C.Nalini,N.Kumar,"An efficient software verification using multi-layered software verification tool "International Journal of Engineering \& Technology, 7(2.21)2018 $454-457$

[18] C.Nalini,ShwtambariKharabe,"A Comparative Study On Different Techniques Used For Finger - Vein Authentication", International Journal Of Pure And Applied Mathematics, Volume 116 No. 8 2017, 327-333, Issn: 1314-3395
[19] M.S. Vivekanandan and Dr. C. Rajabhushanam, "Enabling Privacy Protection and Content Assurance in Geo-Social Networks", International Journal of Innovative Research in Management, Engineering and Technology, Vol 3, Issue 4, pp. 49-55, April 2018.

[20] Dr. C. Rajabhushanam, V. Karthik, and G. Vivek, "Elasticity in Cloud Computing", International Journal of Innovative Research in Management, Engineering and Technology, Vol 3, Issue 4, pp. 104-111, April 2018.

[21] K. Rangaswamy and Dr. C. Rajabhushanamc, "CCN-Based Congestion Control Mechanism In Dynamic Networks", International Journal of Innovative Research in Management, Engineering and Technology, Vol 3, Issue 4, pp. 117-119, April 2018.

[22] Kavitha, R., Nedunchelian, R., "Domain-specific Search engine optimization using healthcare ontology and a neural network backpropagation approach", 2017, Research Journal of Biotechnology, Special Issue 2:157-166

[23] Kavitha, G., Kavitha, R., "An analysis to improve throughput of high-power hubs in mobile ad hoc network" , 2016, Journal of Chemical and Pharmaceutical Sciences, Vol-9, Issue-2: 361-363

[24] Kavitha, G., Kavitha, R., "Dipping interference to supplement throughput in MANET" , 2016, Journal of Chemical and Pharmaceutical Sciences, Vol-9, Issue-2: 357-360

[25] Michael, G., Chandrasekar, A.,'Leader election based malicious detection and response system in MANET using mechanism design approach", Journal of Chemical and Pharmaceutical Sciences(JCPS) Volume 9 Issue 2, April - June 2016

[26] Michael, G., Chandrasekar, A.,"Modeling of detection of camouflaging worm using epidemic dynamic model and power spectral density", Journal of Chemical and Pharmaceutical Sciences(JCPS) Volume 9 Issue 2, April - June 2016

[27] Pothumani, S., Sriram, M., Sridhar, J., Arul Selvan, G., Secure mobile agents communication on intranet,Journal of Chemical and Pharmaceutical Sciences, volume 9, Issue 3, Pg No S32-S35, 2016

[28] Pothumani, S., Sriram, M., Sridhar, Various schemes for database encryption-a survey, Journal of Chemical and Pharmaceutical Sciences, volume 9, Issue 3, Pg NoS103-S106, 2016

[29] Pothumani, S., Sriram, M., Sridhar, A novel economic framework for cloud and grid computing, Journal of Chemical and Pharmaceutical Sciences, volume 9, Issue 3, Pg No S29-S31, 2016

[30] Priya, N., Sridhar, J., Sriram, M. "Ecommerce Transaction Security Challenges and Prevention Methods- New Approach” 2016 ,Journal of Chemical and Pharmaceutical Sciences, JCPS Volume 9 Issue 3.page no:S66-S68

[31] Priya, N.,Sridhar,J.,Sriram, M."Vehicular cloud computing security issues and solutions" Journal of Chemical and Pharmaceutical Sciences(JCPS) Volume 9 Issue 2, April - June 2016

[32]

[33] Priya, N., Sridhar, J., Sriram, M. "Mobile large data storage security in cloud computing environment-a new approach" JCPS Volume 9 Issue 2. April - June 2016

[34] Anuradha.C, Khanna.V, "Improving network performance and security in WSN using decentralized hypothesis testing "Journal of Chemical and Pharmaceutical Sciences(JCPS) Volume 9 Issue 2, April - June 2016 .

[35] Anuradha.C, Khanna.V, "A novel gsm based control for e-devices" Journal of Chemical and Pharmaceutical Sciences(JCPS) Volume 9 Issue 2, April - June 2016

[36] Anuradha.C, Khanna.V, "Secured privacy preserving sharing and data integration in mobile web environments " Journal of Chemical and Pharmaceutical Sciences(JCPS) Volume 9 Issue 2, April - June 2016.

[37] Sundarraj, B., Kaliyamurthie, K.P. Social network analysis for decisive the ultimate classification from the ensemble to boost accuracy rates 2016 International Journal of Pharmacy and Technology 8

[38] Sundarraj, B., Kaliyamurthie, K.P. A content-based spam filtering approach victimisation artificial neural networks 2016 International Journal of Pharmacy and Technology 83 .

[39] Sundarraj, B., Kaliyamurthie, K.P. Remote sensing imaging for satellite image segmentation 2016 International Journal of Pharmacy and Technology 83.

[40] Sivaraman, K., Senthil, M. Intuitive driver proxy control using artificial intelligence 2016 International Journal of Pharmacy and Technology 84.

[41] Sivaraman, K. Kaliyamurthie, K.P. Cloud computing in mobile 
technology 2016 Journal of Chemical and Pharmaceutical Sciences 92

[42] Sivaraman, K., Khanna, V. Implementation of an extension for browser to detect vulnerable elements on web pages and avoid click jacking 2016 Journal of Chemical and Pharmaceutical Sciences 92.

\section{AUTHORS PROFILE}

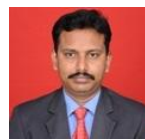

M. Ramamoorthy, Department of CSE, Bharath Institute of Higher Education and Research, Chennai, Tamilnadu, India

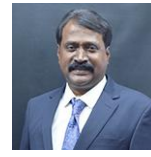

N.Ayyanathan, Department of CSE, B.S. Abdur Rahman Crescent. Institute of Science \& Technology, Chennai, India

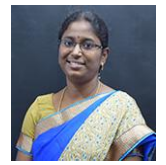

M.Padma Usha, Department of CSE, B.S. Abdur Rahman Crescent. Institute of Science \& Technology. Chennai, India

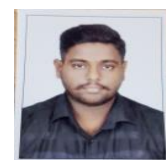

S.Franklin, Student, Department of Computer Science \& Engineering, Bharath Institute of Higher Education and Research, Chennai, India 